\title{
Dynamics of light interception, leaf area and biomass production in Populus clones in the establishment year
}

\author{
G.E. Scarascia-Mugnozza ${ }^{1,2}$, J.G. Isebrands ${ }^{1,3}$, T.M. Hinckley ${ }^{1}$ \\ and R.F. Stettler ${ }^{1}$ \\ 1 College of Forest Resources, University of Washington, Seattle, WA 98195, U.S.A., \\ 2 Institute of Forest Biology, University of Tuscia, 01100 Viterbo, Italy, and \\ 3 Forestry Sciences Laboratory, USDA-Forest Service, Rhinelander, WI 54501, U.S.A.
}

\section{Introduction}

Biomass production in agricultural crops is directly related to the radiant energy interception by foliage (Monteith, 1981). Linder (1985) demonstrated that a linear relationship between solar radiation capture and biomass production also exists for forest stands. However, variability in canopy architecture among plant genotypes could strongly influence the efficiency of conversion of solar energy into biomass production. In this study, we characterized this relationship between light interception and biomass growth on 4 very different Populus clones during the establishment year.

\section{Materials and Methods}

In February 1985, a $1 \times 1 \mathrm{~m}$ plantation was established in Puyallup, WA, U.S.A., with unrooted, $25 \mathrm{~cm}$ hardwood cuttings of 4 poplar clones, including 2 hybrids $P$. trichocarpa $\times P$. deltoides (11-11 and 44-136) and a clone of each of the parental species, $P$. trichocarpa (112 ) and $P$. deltoides (III-5). Growing conditions were near optimal with periodic fertilization and irrigation. Monthly biomass and leaf area measurements were collected from whole-tree harvests of 4-6 trees per clone. Light interception was recorded with a quantum sensor located above the canopy and a quantum line sensor on the ground, below the canopy, connected to integrators. The location of the line sensor was randomly changed every week among permanent growth plots of the 4 clones.

\section{Results}

Light interception of the clones increased throughout the growing season until a maximum value of $95 \%$ (clone 11-11) was reached at the end of September 1985 (Fig. 1). Highest light interception for the clone III-5 ( $P$. deltoides) was only $75 \%$, the lowest value for the study clones; maximum interception for the other 2 clones was intermediate (85\%). At the end of the season (mid-November), the 2 parental clones and hybrid 44-136 had already 


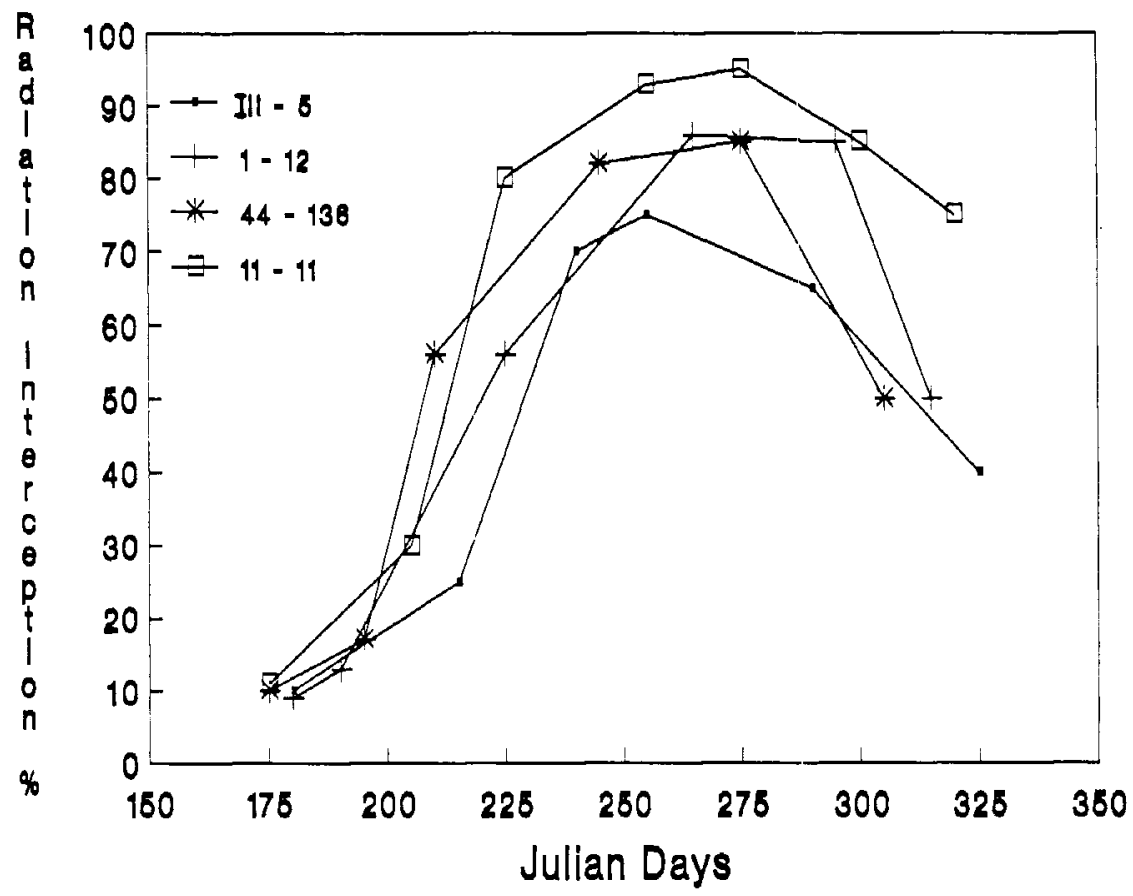

Fig. 1. Changes of light interception in the 4 study clones throughout the growing season. Clones are as follows: III-5: $P$. deltoides; 1-12: $P$. trichocarpa; 44-136 and 11-11: P. trichocarpa $\times$ P. deltoides.

shed all their leaves; however, light interception was still around $45 \%$, apparently because of the absorption of radiation by stem and branches. At that time, hybrid clone 11-11 still retained part of its foliage and light absorption was around $75 \%$.

Light absorption by a clone was directly related to its total leaf area (Fig. 2); again hybrid 11-11 had the maximum leaf area index (LAI) (2.9), followed by hybrid 44$136(1.5)$ and the 2 parental clones, $P$. trichocarpa (1.2) and $P$. deltoides (1.0). Large differences existed among poplar genotypes in crown structure; in clones $11-11$ and $1-12$, almost $50 \%$ of the total leaf area consisted of leaves on branches, whereas in the other 2 clones, 44-136 and III-5, this proportion was only $15 \%$ (Fig. 2).
In contrast to the differences in total $L A I$, the 2 hybrid clones had quite similar $L A I$ values for leaves on the main stem.

Ranking of clones for biomass production during the establishment year was similar to that of light interception and $L A l$; the average tree of hybrid clone 11 11 produced a total biomass of $1 \mathrm{~kg}$ of dry weight, while only $0.4 \mathrm{~kg}$ were produced by $P$. deltoides clone III-5. The linear regression of cumulative biomass on cumulative intercepted radiation of the 4 clones had an $R^{2}$ of 0.87 , with a conversion efficiency of $0.55 \mathrm{~g} \cdot \mathrm{MJ}^{-1}$ (Fig. 3). This parameter showed large variability among clones with the highest value occurring in clone $11.11\left(0.8 \mathrm{~g} \cdot \mathrm{MJ}^{-1}\right)$ and the lowest in III-5 $\left(0.4 \mathrm{~g} \cdot \mathrm{MJ}^{-1}\right)$. 


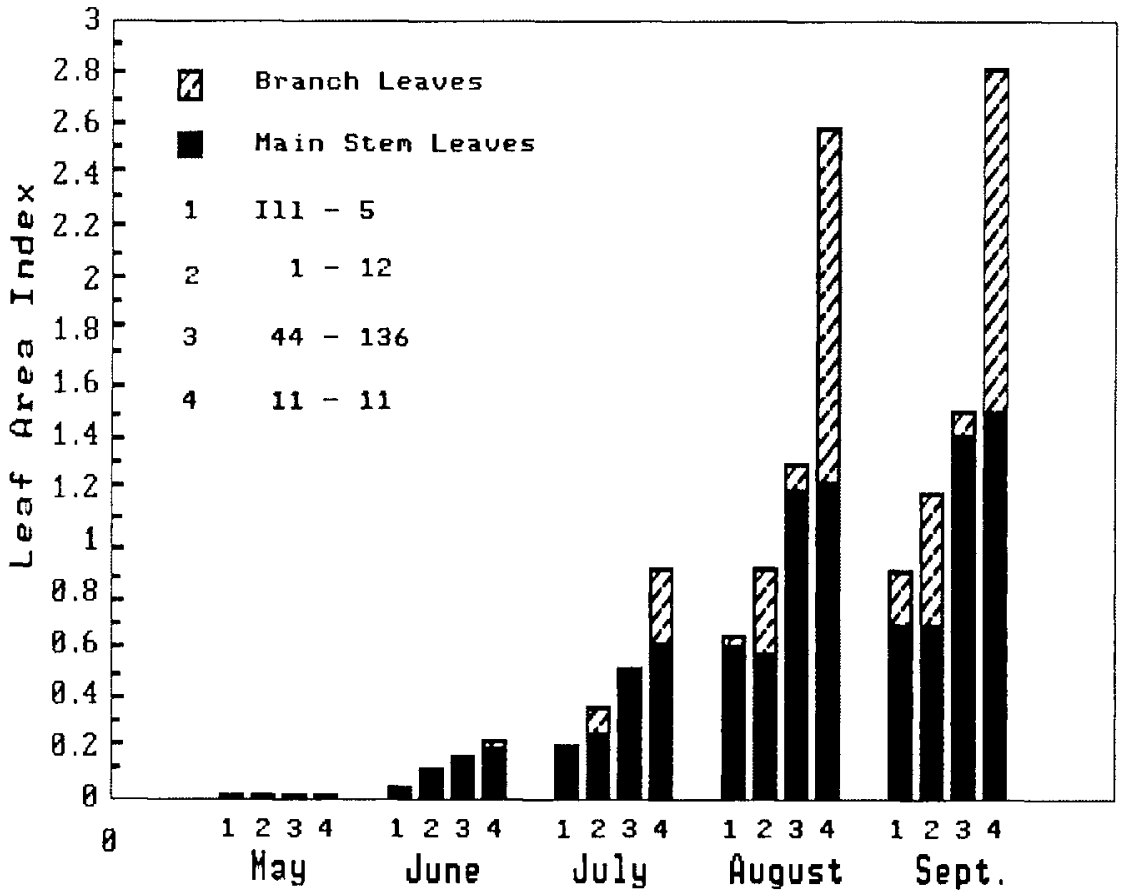

Fig. 2. Changes of leaf area index and its distribution in the 4 study clones throughout the growing season. Clones are as described in the legend to Fig. 1.

\section{Discussion and Conclusion}

Total biomass production by $P$. trichocarpa $\times P$. deltoides hybrid clone 11-11 was 2.5 times that by the parental clone III-5 ( $P$. deltoides), although it should be noted that the latter is not native to the Pacific Northwest. The significant relationship between biomass growth and leaf area or radiation interception has also been observed by Zavitkovski et al. (1976) on Populus and by Linder (1985) on Eucalyptus, although for this latter genus only indirect estimations of light interception were used. In the present study, the linear regression between light interception and biomass production gave a high $R^{2}$ value, although a curvilinear function might be more appropriate. This indicates that the efficiency of energy conversion into biomass changes throughout the growing season and for a given plant material.

Another significant source of variation in the conversion efficiency is the genotype, even within the same species or the same genus. The 2 hybrid clones (11-11 and 44-136) used in this experiment showed the highest conversion efficiencies, compared to the parental clones. Even though their total leaf area indices at the end of the growing season were quite different, their leaf areas on the main stem 


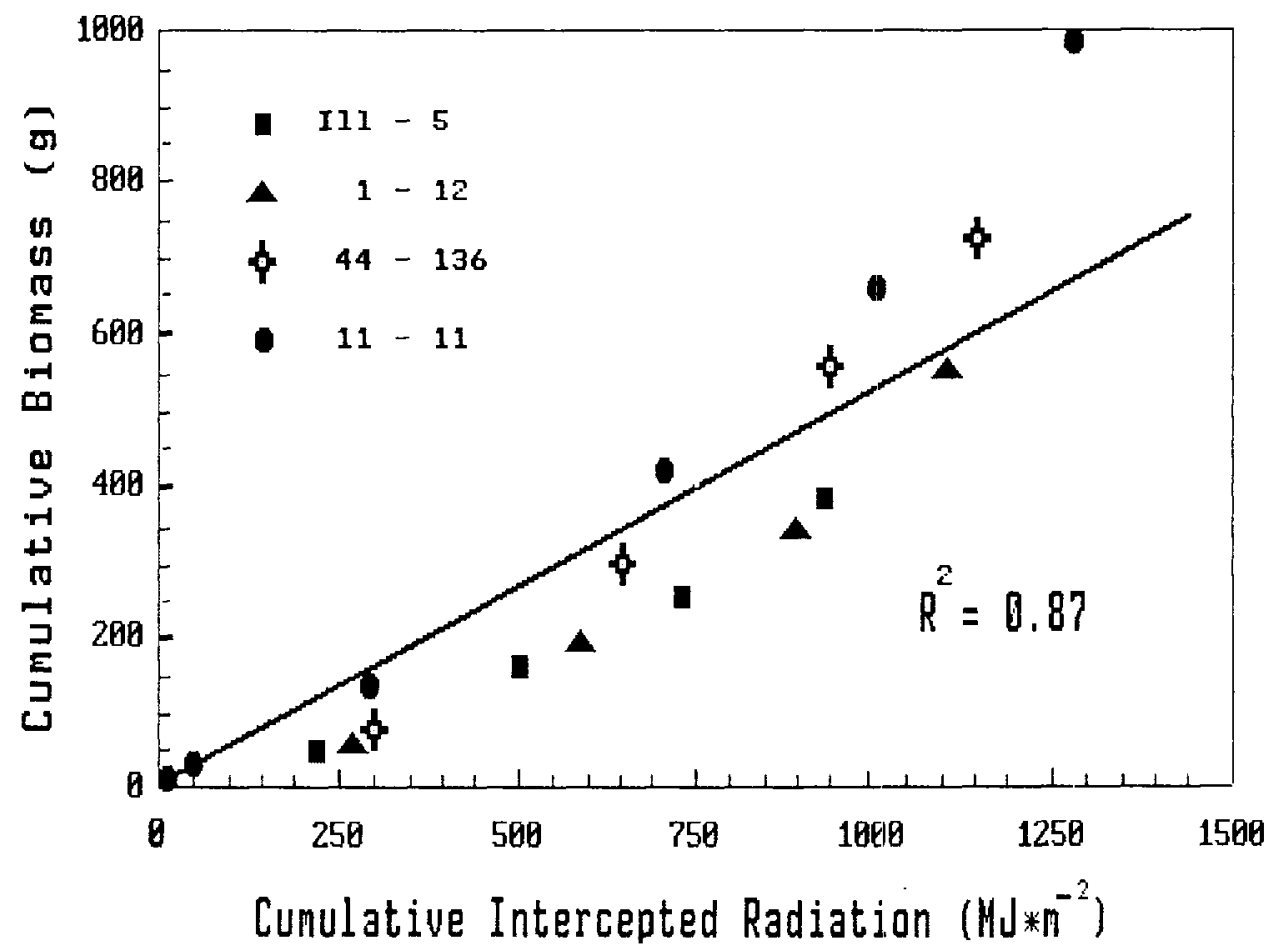

Fig. 3. Relationship between biomass and intercepted radiation in the 4 study clones. Clones are as described in the legend to Fig. 1.

were almost the same; these leaves are by far the most efficient for light conversion into biomass, as shown by Isebrands et al. (1983).

Crown architecture, that is the combination of total leaf area, leaf area distribution within crowns, leaf and branch morphology and orientation, seems to play a major role, since it influences not only the interception of solar radiation but also its conversion into biomass.

\section{Acknowledgments}

Research performed under subcontract no. 19X-43382C with Oak Ridge National Laboratory under Martin Marietta Energy Systems, Inc. contract DE-AC05-840R21400 with the U.S. Department of Energy.

\section{References}

Isebrands J.G., Nelson N.D., Dickmann D.I. \& Michael D.A. (1933) Yield physiology of short rotation intensive cultured poplars. In: Intensive Plantation Culture: 12 Years Research. (Hansen E., ed.), USDA For. Serv. Gen. Tech. Pap. NC-91. pp. 77-93

Linder S. (1985) Potential and actual production in Australian forest stands. In: Research for Forest Management (Landsberg J.J. \& Parsons W., eds.), CSIRO, Melbourne, pp. 11-35

Monteith J.L. (1981) Does light limit crop production? In: Physiological Processes Limiting Plant Productivity. (Johnson C.B., ed.), Butterworths, London, pp. 23-38

Zavitkovski J., Isebrands J.G. \& Dawson D.H. (1976) Productivity and utilization potential of short-rotation Populus in the Lake States. In: Proc. Symp. on Eastern Cottonwood and $R \theta$ lated Species. (Thielges B.A. \& Land S.B. Jr., eds.), Louisiana State University, Baton Rouge, pp. 392-401 